\title{
Philipp Frank at Harvard University: His Work and His Influence
}

\section{Citation}

Holton, Gerald. 2006. Phillip Frank at Harvard: His Work and his Influence. Synthese 153 (2): 297-311. doi.org/10.1007/s11229-005-5471-3

\section{Permanent link}

http://nrs.harvard.edu/urn-3:HUL.InstRepos:37837879

\section{Terms of Use}

This article was downloaded from Harvard University's DASH repository, and is made available under the terms and conditions applicable to Other Posted Material, as set forth at http:// nrs.harvard.edu/urn-3:HUL.InstRepos:dash.current.terms-of-use\#LAA

\section{Share Your Story}

The Harvard community has made this article openly available.

Please share how this access benefits you. Submit a story. 
Lecture at Philipp Frank Conferences in Prague \& Vienna, Sept-Oct. '04

\section{Philipp Frank at Harvard: His Work and his Influence}

by Gerald Holton

My pleasant task today is to bring to life Philipp Frank's work and influence during his last three decades, when he found a refuge and a position in America. In what follows, I hope I may call him Philipp--having been first a graduate student in one of his courses at Harvard, then his teaching assistant sharing his offices, then for many years his colleague and friend in the same Physics Department, and finally, doing research on his archival holdings kept at Harvard. I also should not hide my large personal debt to him, for without his recommendation in the 1950s to the Albert Einstein Estate, I would not have received its warm welcome and its permission, as the first one to do historical research in the treasure trove of unpublished letters and manuscripts, thus starting me on a major part of my career in the history of science.

Philipp's work may be thought to have had a different main focus during each of these successive phases: while he was in Vienna until 1912, in Prague to 1938, and finally in America to 1966. But one can also find throughout continuing developments of Philipp's deeply motivating intellectual ambition. As we know from his partly autobiographical account, that ambition started in a seemingly accidental way, when around 1907, as a 23-year-old with his brand new physics doctorate, as he put it, "mostly from Boltzmann," he began to meet in Vienna with other young men, including Hans Hahn and Otto Neurath, where they discussed a wide range of problems - in science, philosophy, politics, history and religion. A key event was reading and discussing Abel 
Rey's new book, La Théorie de la Physique chez les Physiciens contemporains (1907). I shall return to this point, because in terms of intellectual history, reading Rey's book at that time had important consequences.

While the philosophy of science was a strong interest of Philipp at that time, it still was for him on the sideline compared with his many publications on physics and mathematics. Between 1908 and 1912, Philipp published 15 papers, most of them solid ones on relativity theory, at a time when very few (e.g., Max von Laue and Paul Ehrenfest) had been major contributors in that field.

In Philipp's second phase, the one in Prague, the mixture of his interests continued, but philosophy of science took more of the center stage as time went on. In the last phase, after his arrival in his mid-'50s in the United States, despite initial severe handicaps as we shall see, his work flourished almost extravagantly into a multitude of activities and organizations on behalf of his worldview, at a scale even more expansive than in the earlier decades.

This is precisely my task today: to sketch, in the brief time available, some of the underlying continuities in Philipp's development, and the final achievements of his mature intellectual agenda.

\section{Arrival}

Coming from Prague via a conference in England, Philipp arrived in the United States in October 1938, only two years after the Austrian government had forced the Vienna Circle to close. He came to give invited lectures at over twenty colleges and universities, a tour to last until late December 1938, after which (as he wrote in a letter of 19 August 1938) at the end of December he would "be back in Prague for good." Now in his mid-fifties, he was received in the U.S. as a distinguished and admired exemplar of the Central European intellectuals and scholars, like many who had already made the U.S. aware of those treasures. After all, Philipp was the Director of the Institute for Theoretical Physics at Prague University, he had been Einstein's successor there since 1912, at Einstein's own recommendation. As scientist-philosopher, Philipp was a link in the charismatic chain from Mach to Poincaré to Boltzmann; and not least, the Frank- 
Mises volumes on differential and integral equations had been for many years the text on the subject for physicists in the U.S.

Moreover, the earlier visits to the United States by Hermann Feigel and Moritz Schlick had prepared the ground for audiences there for Philipp's philosophical message; and in any case many in America were already sympathetic to Philipp's ideas, having their own, native series of distinguished positivists and pragmatists of various sorts, such as Johann Stallo, William James, C. S. Peirce, John Dewey, and P. W. Bridgman. Many American scientists and philosophers had also read Ernst Mach, because thanks to Paul Carus a large fraction of Mach's work was published early in English, some of it in fact before its German publication. An indication of how ready Philipp's audiences were to welcome him appears in a letter Bridgman wrote (30 March 1938) to Philipp, half a year before his arrival in the U.S. "I read [the reprints and the books you sent] with very great interest. It is naturally a source of gratification to me that we can agree on so many points....It will be a great pleasure to see you in Cambridge next fall and to talk things over with you."

Among the universities Philipp visited during that time, one was Harvard University, where he spoke in early December 1938 on "Philosophical Interpretations and Misinterpretations of Quantum Theory." But by that time, Philipp was well aware that his home country, Czechoslovakia, was being betrayed by its spineless Allies, was being torn into pieces and handed over to the Nazis. Most Austrians had already offered themselves to Hitler's gangsters in March 1938. That "victory" showed Hitler how easy it would be to deal with Neville Chamberlain in Munich in late September 1938, and then to proceed with the annihilation of the Czechoslovak state in stages, ending in March 1939. These German "successes" resulted in a momentous expansion of Hitler's perception of what he could do with the rest of Europe. The gates of hell would soon swing wide open; among the many victims would soon be Philipp's colleagues caught back in Prague, including the mathematician Georg Pick and the chemist Hans Leopold Meyer, both dying in 1942 in one of the concentration camps.

When Philipp had arrived in the U.S. with his wife Hania for that lecture tour, they had only short-term Visitor's visas, meaning that they would not be allowed to stay long. But given the increasingly dangerous situation in Prague, they also could not dare 
to return. Everything Philipp had worked for there for twenty-six years-- his position, his colleagues and students, their friends, their home - it all had to be abandoned. As Prague fell, Philipp's position in the U.S. changed suddenly and drastically, from being initially a distinguished visitor to being now a displaced person without a job. It was a terrifying situation for both of them. As Philipp wrote to Melanie Serbu in Romania later: "[My Wife and I] have overcome the initial shock, washed ashore here and had to build up a completely new existence out of nothing. We have again started entirely from the beginning, which at this stage is not so easy."

\section{Entering Harvard}

Clearly, Philipp now needed an academic position, both to survive in the U.S. and to get a non-quota visum that would allow him to stay. In principle, this should not have been difficult. Enough American intellectuals were already partial to the work he had done and had embodied.

And of all places in American academe, Harvard University, although in those last years of the Great Depression still a relatively small and poor institution, should have been among the first to offer Philipp a home. After all, in addition to Philipp's admirers, Bridgman and Edwin C. Kemble, there were on the faculty the great astronomer and sympathizer, Harlow Shapley, and the powerful philosopher, W. V. Quine, who in fact had been a pilgrim in the 1920 s to absorb the Vienna Circle message by going directly to Vienna and Prague. Moreover, Harvard University had already given asylum to six refugee professors.

But now there ensued a rather demeaning period of indecision at the level of the Harvard Administration. Having already given those six asylum fellowships was now thought to be the limit for this university. And also, Philipp being both a philosopher and a physicist, there was not one obvious department ready to receive him in both capacities.

I don't recommend to anyone to read in the Harvard University Archives the correspondence between those who wanted to find a position for Philipp at Harvard-for example, the Department of Physics, which sent a unanimous motion to the Administration in favor of an appointment—and, on the other hand, the Administration's 
responses. It is very dispiriting. Philipp and Hania must have lived in almost unbearable suspense.

But the continuous push by the scientists, and particularly by Shapley, Bridgman and Kemble on the Administration, finally worked, and Shapley could send a letter to Frank that he would be given a one-year position, starting September 1, 1939, provided, however, that it was at no cost to the University. Ever ingenious and active on behalf of many refugees, Shapley himself raised \$2000 as Philipp's salary for the year. Luckily, Philipp could supplement this most inadequate amount by an advance from the publisher A. A. Knopf for the Einstein biography, which his wife had suggested he write, and for which Philipp now had a contract. But thereafter, practically year after year, the same fight ensued, to find a paying position and a home department for Philipp, usually at halftime and with most inadequate titles. He, the scientist-philosopher known the world over, now had to settle for the title of Research Associate, and, finally, Lecturer, which corresponds to the German Privatdozent, the very title Philipp had when he started on his career as a very young man in Vienna. During the part of the year when he was free from his half-time obligation at Harvard, Philipp had to find opportunities to teach at other universities.

Philipp's first Harvard appointment, in physics and philosophy, was to start on the first of September 1939. What an ominous date! World War II began that day in Europe, although America remained largely asleep. But by extraordinary irony, within two days of that date there occurred an event at Harvard University that denoted the rise of Philipp again to the high level which he deserved in terms of intellectual influence. For, as it happened, the week-long Fifth International Congress for the Unity of Science, on "Logic of Science," had long been scheduled to begin on September 3, 1939 at Harvard University. Bridgman and Quine were effectively the convokers, with Philipp Frank at their side. In an act of clever politics, they had interested President James Bryant Conant of Harvard to be the official greeter at the first session. Philipp appeared prominently on the program twice, once with the lecture on 'Einstein's Theory of Relativity in the Evolution of Science," and then as the summarizer of the whole Congress at its end on September 9. 
In an almost surrealistic way, during the days of that Congress, many of Philipp's colleagues and friends from the days in Europe assembled before and around him. ${ }^{1}$ One of them was Richard von Mises, who later became Professor of Applied Mechanics at Harvard, located in the building next to Philipp's.

\section{Teaching}

One might have thought that Philipp was left dispirited by his turbulent odyssey between October '38 and September '39, and of course by the rape of Czechoslovakia. But no. Philipp, while always sounding and looking so gentle, was tough as steel inside. Starting from that September '39 Congress, he vigorously went ahead with the four main elements of his agenda.

The first of these elements was teaching physics and philosophy at Harvard, chiefly courses in relativity, dynamics, thermodynamics, and philosophy of science. In one course called "Contemporary Physics and its Philosophy, a Philosophical Interpretation," he started with 15 students and after a while had 250 (hence the need for teaching assistants like me). It was the first time at Harvard that undergraduates, even in their first year, could discuss relativity and quantum theory.

There are many stories about Philipp's admired style of teaching, but it may suffice here to quote the official Harvard weekly, the Gazette, which later reported (December 30, 1967, Obituary), that Philipp taught with "almost deceptive simplicity. He could explain so simply because he understood so clearly." That friendly style was already in place in his Prague years.

From my own perspective, Philipp's teaching contained an only slightly hidden agenda, namely, to open his students' minds and sympathy to a modern scientific worldview. When I later encountered students from those courses, they generally thought of them as the highpoint of their college education.

\section{$\underline{\text { Publications }}$}

\footnotetext{
${ }^{1}$ For the list of expected persons and the titles of their lectures at the Congress, and for many additional points connected to this essay, see my chapter, "On the Vienna Circle in Exile: An Eyewitness Report," in W. DePauli-Schimanovich, et al. (eds.), The Foundational Debate (Kluwer Academic Publishers, 1995), pp. 269-292.
} 
The second of the elements in Philipp's agenda in those years was of course to continue to publish, primarily as a missionary, as a scientist, philosopher and humanist. During his 28 years in America, Frank published, often under difficult circumstances, no less than 50 articles and books, chiefly on the physical, philosophical, psychological, social, historical and cultural aspects of science. Unlike some others in the Vienna Circle, Philipp already had that generalizing program in Europe, as we know for instance from Carnap's Autobiography, and even from Philipp's own long list of topics of discussions held with his friends, starting in 1907.

Above all, there was Philipp's biography of his long-time friend, Albert Einstein (published in 1947). That book is still one of the best in the English language, not least by virtue of giving the historical, philosophical and cultural context, even though the manuscript of his book was horribly mangled by its publisher. Alfred A. Knopf gave the manuscript to an American who, Philipp told me, knew English but no science, and also to a Japanese who knew science but no English. Between the two, Philipp's original German manuscript was severely truncated. Happily, List Verlag in Germany published Philipp's original manuscript of his book, and even was persuaded, in a recent reprinting, to include Einstein's Preface, which Knopf had vetoed.

\section{Organizations}

The third point on Philipp's old agenda, now revived in the New World, was as I hinted already, to missionarize on behalf of his Wissenschaftliche Weltauffassung, as it had been developing since Philipp's days in the discussions in the Viennese coffeehouse. He pursued his constantly enlarging version of the Enlightenment Project, assumed as his joyful duty as a public intellectual and Kulturträger, but also corresponding to his psychological needs. As Ernst Nagel put it, "The philosophy of science at the hands of Frank is a profoundly liberating discipline."

As part of that mission, Philipp, in 1947, founded and assumed the presidency of a new organization, which he called the "Institute for the Unity of Science." It had an ambitious agenda of meetings and publications. Earlier, he founded a monthly "Interscientific Discussion Group," in which I, as by far the youngest, was easily persuaded to be the Recording Secretary. I have told some details about that discussion group in a 
conference on the Vienna Circle in Prague in $1988,{ }^{2}$ but would like to indicate briefly the quality of this typical Philipp Frank enterprise.

On March 21, 1945, the group met as usual in the Harvard Faculty Club, to hear and discuss the biologist George Wald's presentation. On that particular occasion, among the 32 persons present, the list of signatories on the circulated attendance form that still exists contained, over a wide range of specialties, such well known scholars and scientists as G. Kurti, Talcott Parsons, John Edsall, Gottfried Haberler, Harlow Shapley, J. Schumpeter, C. J. Ducasse, Norbert Wiener, I. A. Richards, George E. Uhlenbeck, and G. de Santillana. But there also were present at that meeting four more, each of whom later received a Nobel Prize: George Wald, Paul A. Samuelson, Wassily Leontief, and P. W. Bridgman.

In the accounts of other meetings of the group over the years, there would appear names such as Quine, Richard von Mises, Hermann Bondi, Karl Popper, Howard Aiken, John von Neumann, Oskar Morgenstern, Denis Gabor and Alexandre Koyré. Let me only add the obvious: What a privilege it was for this young Recording Secretary to be there, to listen, and to participate.

The list of Philipp's activities I have given by no means exhausted his energies. Philipp also helped to organize the Boston Colloquium for the Philosophy of Science, which was headed by Professor Robert S. Cohen at Boston University, and is vigorously active to this day. Moreover, Philipp acted during those years in the U.S. as Editor or Associate Editor of several journals, and participated regularly in such conferences as the annual Conference on Science, Philosophy, and Religion (in New York City).

But that, too, was not enough. Many institutions and colleagues were subtly but effectively persuaded by this charming, mild-mannered and weltfremde man to throw themselves into arranging public conferences and producing papers for them. One example of those long-remembered conferences was the one on "Validation of Scientific Theories." Philipp arranged it to be held in Boston in December 1953, conveniently as a joint meeting of the large American Association for the Advancement of Science that just happened to have its meeting that year in Boston. In fact, it was a striking replay of the great coming-out party of the Vienna Circle, namely the 1929 meeting which Philipp had

\footnotetext{
${ }^{2}$ See Ref. 1.
} 
organized in Prague, just when the German physicists happened to be having their meeting in town.

\section{Bridging and Growing}

A fourth part of Philipp's agenda was a desire and ability to bridge differences, not only between science, philosophy and the rest of culture, but also between people and their differing passionate ideas. Thus, in his early years, he could live with both Mach and Boltzmann, and he tried to bring together apparently opposite ideas, such as those of Ernst Mach and Henri Poincaré, by combining them in his form of empiricism. Along the same lines, Philipp succeeded in getting President Conant of Harvard, who initially did not help him obtain an appointment, to participate in a conference held at Philipp's Institute for the Unity of Science, and Conant also listened carefully to Philipp's arguments in favor of what eventually became part of Conant's chief legacy, the General Education program at Harvard College.

\section{Probability vs. Absolutism}

As I was studying Philipp's career from documents and comparing them with what I had seen at first hand, it was clear that despite the long time lapse and many relatively small changes, Philipp at Harvard was at heart still Philipp in his early years in Europe, when the late $19^{\text {th }}$-century banner of the "Bankruptcy of Science" was still flying. I mentioned earlier that Philipp was captivated as a very young man by Abel Rey's book of 1907, which warned that the loss in the late $19^{\text {th }}$ century of the authority of the old, absolutely classically causal mechanistic science had caused the unity-seeking goal of science to give way to diversity, and opened the floodgates to metaphysical misinterpretations of science as well as theological mystifications. In opposition, Philipp published his important and adventurous paper on "Causality and Experience" in 1907, at age 23 (later, his 1932 Kausalgesetz book was based on it). In that paper, which shortly became a key step in Philipp's career because it opened a correspondence with Einstein, Philipp countered the notion that science was doomed, by adopting an extreme view of Poincaré's conventionalism. In a key passage, he wrote: "The law of causality, the 
fundament of every theoretical natural science, can be neither confirmed nor disconfirmed through experience.....because it is a purely conventional statement."

Here I want merely to point to one related aspect in the fight waged by Philipp and his circle. In those early years of the twentieth century, the new thermodynamics and radioactivity opened a new front for the empiricists to attack absolutes, by embracing the notion of the primacy of statistical laws. As student of Boltzmann, Philipp would have become thoroughly aware of the statistical and probabilistic view as an alternative to the ancient one of Newtonian absolutes. This was undoubtedly reinforced by his awareness, as a student at the University of Vienna, of the work of the great expert on radioactivity, Franz Exner, himself a former Boltzmann student. In an interview in 1962 (Sources of Quantum Physics project), Philipp recalled that Exner gave a famous talk "about the role of statistics in physics....He said it may be that the basis of physics would be statistical." Philipp added: "And it existed also of course in this Einstein fluctuation theory, too, because in the fluctuation theory....the statistical law is the primary law." Philipp did not need to add that the attack on absolutes had been raised also in Ernst Mach's work, and in Einstein's Relativity, which destroyed the notions of absolutes of space, time, and simultaneity.

Abel Rey himself frequently summarized his ideas in the remark: "Real scientific truth lies in its historical curve. It never lies on one point of the curve." Correspondingly, one of Philipp's books in his years in America, Relativity, the Richer Truth (1950) - a subject of an excellent analysis by Dr. Elizabeth Nemeth in 2000 — was essentially an extended argument against the evils of absolutism. As an aside, one should be aware that anti-absolutism was also a not-well-hidden fight against the stronghold of Austro-clericism on the universities and on intellectual and political life. For example, in his 1907 article on the Kausalgesetz, Philipp ended the last paragraph — as if to make sure not to spare his more clerically minded readers - with the telling and surprising sentence: "With a worldview in the ethical-religious sense, all this has nothing whatever to do."

It is not my task here to pursue further the fascinating, long history of the connection between the opposition to absolutes and absolutism on the one hand, and the embracement by the logical empiricists generally of probabilities on the other. It is a subject worth serious study. One study of this case is part of a dissertation just finished 
by a graduate student at Harvard University, Deborah R. Coen. Her dissertation is entitled "A Scientific Dynasty: Probability, Liberalism, and the Exner Family in Imperial Austria." Another interesting source is the article "Franz Serafin Exner's Indeterminist Theory of Culture," by Michael Stöltzner (Physics in Perspective, v. 4 [2000], pp. 267319).

By the turn of the century, three well placed Exners in Vienna, a physicist, a physiologist, and a jurist, were denying and ridiculing absolutism in the various fields. I am not suggesting that one can draw a straight line from the rebellions against absolute authority in the late 1840s to Philipp Frank's demystification of the Kausalgesetz, or from Franz Exner's lecture (to which Frank in fact referred twice in his book, Kausalgesetz) to the revolutionary ideas embedded in the Vienna Circle Manifesto. Yet, there are here parallelisms and convergences that deserve much further study.

\section{$\underline{\text { Retirement and Old Age }}$}

In 1954, at age 70, Philipp had to retire from Harvard, at about the same time as did Bridgman, who had been my doctorate thesis supervisor. Since no one else seemed to be arranging a real retirement party for them, I went ahead on my own to assemble a meeting in their honor, with a helping committee containing Karl Deutsch, Roman Jakobson, Harlow Shapley, B. F. Skinner and W. V. Quine. The occasion (May 5-6, 1956) was suitably entitled "Science and the Modern Worldview-Toward a Common Understanding of the Sciences and Humanities." Both Frank and Bridgman gave lectures, and most of the papers were published in early 1958 as the first issue of the new quarterly journal Daedalus, of which I was Editor-in-Chief. ${ }^{3}$

For Philipp, "retirement" meant simply setting out for new conquests. Having no longer an office at Harvard, he found a home at the American Academy of Arts and Sciences, and obtained a fine contract for scholarly work from the National Science

\footnotetext{
${ }^{3}$ The Conference on "Science and the Modern World View: Toward a Common Understanding of the Sciences and the Humanities," held at Cambridge, MA, was sponsored by the American Academy of Arts and Sciences and the Institute for the Unity of Science. On the list of people who agreed to come to what turned out to be a quite touching and intellectually stimulating occasion, were the presidents of Harvard and of the American Academy, John Burchard, Ernest Nagel from New York, Giorgio de Santillana, Henry Guerlac, Harcourt Brown, Perry Miller, I. I. Rabi, Robert Oppenheimer, Jerome Bruner, W. V. Quine, the head of the National Academy, Detlev Bronk, Charles Morris, Howard Mumford Jones, Meyer Shapiro, and of course Bridgman and Frank.
} 
Foundation, to do a series of books on the topic "The Reasons for Accepting Scientific Theories." Those reasons, according to his funding application, included the following: logical, empirical, psychological, philosophical, and sociological. (Once more, the spectrum matches well that of the 1907 discussions.) There exists in Philipp's section in the Harvard Archive a fat file, including lots of difficult-to-read handwritten pages, which I believe to be largely drafts for parts of those promised books, which, however, never saw print. ${ }^{4}$ But four pamphlets of essays, edited by Philipp, did appear in the Academy's publication series.

By 1964, both Philipp's and Hania's health was deteriorating. The physicist Laszlo Tisza of MIT, my wife Nina and I grew increasingly concerned, and ultimately we found an adequate nursing home in Cambridge for them. It took some time to persuade them to go there. The downward spiral had begun. I feel sad to report that Philipp's pension from Harvard was very small, because he had arrived late, had had only a low salary there, and was mostly kept at half time. I hope the inadequate pension was supplemented by some royalties from Philipp's books. Not unexpectedly, Philipp never complained about any of that. The only hint of his mental condition came when, on his admission, the nurse showed him the small common room with a TV set in it. She said cheerfully: "That is our activity room." To this, Philipp said with his gentle smile, "Dear Miss, what I need is a passivity room."

Some of his friends visited both Franks as often as they could. At one of these visits, the nurse told me that Philipp for some days had been refusing all food. I argued forcefully with him that a mere push on a button near his bed would bring food whenever he was hungry. He quietly replied: "You are still too young to appreciate it, but death is also a natural phenomenon." Those were the last words I heard from this true philosopher.

\footnotetext{
${ }^{4}$ Kurt Sitte, one of Philipp's former students in Prague, wrote (Boston Colloquium) that a colleague there "was given the hard task of typing out Philipp Frank's manuscript for his Kausalität book. Half the time she was in despair because she could not read his handwriting. She came to me for succor. I faired no better in reading, but with a few clues deciphered, I managed to dictate 'what Frank would have said' on the subject mater... There were a few occasions when we both failed, and we had to go to Philipp Frank for elucidation: in these cases, we found that he, too, could not read his manuscript, but quickly formulated a new version."
} 
He died a few days later, on 21 July 1966, a year and a half before Hania's death. A small service for Philipp was held at a funeral parlor in Boston before his burial. When Philipp's friends had gathered in the funeral parlor, a man came in whom none of us had ever seen before. He explained himself as follows: He was one of the gardeners in Harvard Yard, and had been working there for some years. He had seen Professor Frank often on his way to Harvard Square, and by and by the gardener had begun to greet him. Every time they met again after that, Professor Frank had not only greeted him but in so doing had raised his hat. That had moved the gardener so deeply that on being told of Professor Frank's death, he felt he had to say goodbye to him. There is in this story a hint of Philipp's personal charisma.

On October 25, 1966, Philipp's colleagues held a public memorial service at Harvard. The expressions of appreciation were contributed by Peter G. Bergmann, Jeremy Bernstein, Joseph T. Clark, S.J., Robert S. Cohen, myself, Edwin C. Kemble, Ernest Nagel, and Laszlo Tisza. The official Gazette of the University ended its biographical Memoir with these words: that with Philipp's death, there "ended a gentle, beneficent, and prolific life that gave the world far more than the world gave in return."

\section{Epilogue}

Finally, what became of it all? Certainly, Philipp and his colleagues in the 1920s and early 1930s had caused a Turn in Philosophy of Science, once and for all. His books continue to be important. I regularly get mail from people who are writing articles or dissertations on his work. But the dream of the unity of science seemed soon to be ending, possibly even at the very conference of 1956 which I had arranged and published. For in a speech at that meeting, contrary to most others, Robert Oppenheimer had, perhaps presciently or prematurely, predicted that for the time being the energy to reach that old aim of unification had run out. As he put it in his lecture (pp. 75, 76, Daedalus, Winter 1958):

"It may be a question [whether there] is one way of bringing a wider unity in our time. That unity, I think, can only be based on a rather different kind of structure than the one most of us have in mind when 
we talk of the unity of culture....the unity we can seek lies really in two things. One is that the knowledge that comes to us in such terrifyingly inhumanly rapid rate has some order in it....The second is simply this: We can have each other to dinner. We ourselves, and with each other by our converse, can create, not an architecture of global scope, but an immense, intricate network of intimacy, illumination, and understanding."

It is now nearly five decades since this valedictory to the unity of science was pronounced. But two things have happened that may well be bringing us back to the very point when young Philipp picked up that book by Abel Rey, and saw in it a demand to stem the demeaning of science, and to fashion a new authority for science. During the last few decades powerful claims against science have again been asserted, at least in academe in English-speaking countries, raising once more the banner of the "Bankruptcy of Science." I need not give you examples of the excesses of postmodern and constructivist misinterpretations. You know them well.

We are in some ways right back at the place where Philipp took up his battle on behalf of the rational analysis of science and its philosophy in the wider culture of the day. How we need him now! He would have again a hard missionary task. But he would also have many allies. Moreover, something new has been happening to help him and us. I mean that scientific research over these past few decades is reaching more and more for a new sort of unity or integration. This time this is not driven by philosophy of science or a search for unity with philosophy, but is appearing as if spontaneously in the progress and pursuit of science itself. There is a new and increasing coalescence of scientific disciplines in many areas. Thus the discovery of the structure of the genome not only required contributions from parts of physics, chemistry, biology, mathematics, and information technology, but in turn it led to further advances in biology, chemistry, physics, technology, medicine, ecology, and even ethics. And all this scientific advance, as Philipp always insisted, led, as it should, to the hopeful betterment of the human condition, as had also been announced in the last sentence of the Vienna Circle's Manifesto of 1929.

Similar developments happen in the physical sciences - a coalescence of particle physics and large-scale astronomy, of physics and biology, and so forth. It is a telling 
indicator that about half of my 45 colleagues in Harvard's Physics Department now have joint appointments with other departments at the University, owing to their widespread research interests: with Molecular and Cellular Biology, with Mathematics, with Chemistry, with Applied Sciences and Engineering, with History of Science. Just now, a new building is being erected next to our Physics Department. It has the acronym LISE, which stands for the remarkable name, Laboratory of Integrated Science and Engineering. Similarly, from other parts of this university, plans are under way to set up a program for higher degrees in the new field of Systems Biology, which has the goal of reaching "an integrated understanding" of biological/medical processes; that program is designed to bring together faculty and students from biology, medicine, chemistry, physics, mathematics, computation and engineering. Throughout academe, not only in science, but also in social studies and in the humanities, a new password to success is now "integration" and "interdisciplinarity." The same applies to many segments of industry.

All this is not precisely what Philipp, Otto Neurath, and their friends were fighting for throughout the three phases of Philipp's life, not least because it is rather less engaging philosophically. Nevertheless, something new is trying to be born. Otto Neurath, in vol. 1, no. 1 of the International Encyclopedia of Unified Science (University of Chicago Press, Chicago, 1938, p. 20) already had foreseen it, writing that "science itself is supplying its own integrating glue, instead of aiming at a synthesis on the basis of a 'super science' which is to legislate for the special scientific activities."

So there is a hint of a new order that is coming to us with that new knowledge, and there is a possibility of new kinds of unities. If Philipp Frank were now with us, he would be among the first to understand it--and explain it to us. 